\title{
In vitro study of the influence of strain rate on the strain at dissection of atherosclerotic arteries during balloon inflation
}

\author{
Jacco LG Steenhuijsen", student member IEEE, Simon R Vaartjes ${ }^{+}$, Cees J Poortermans ${ }^{+}$, \\ Herman BK Boom*, member IEEE. \\ *Institute for Biomedical Technology, University of Twente, PO Box 217, 7500 AE Enschede, The Netherlands \\ ${ }^{+}$Hospital Medisch Spectrum Twente, PO Box 500007500 KA Enschede, The Netherlands \\ email: J.L.G.Steenhuijsen@el.utwente.nl
}

\begin{abstract}
Long term successrate of Percutaneous Transluminal (Coronary) Angioplasty (PT(C)A) is limited by restenosis. Arterial lesions have been related to restenosis, although the nature of this relation is still unclear. Because the arterial wall structure has both elastic and viscous properties, we expect the mechanical behaviour of the arterial wall during angioplasty to be strain rate dependent. We here describe the results of our experiments to test the influence of strain rate on the strain at the moment of dissection during angioplasty. Keywords: angioplasty, strain rate, dissection
\end{abstract}

\section{Introduction}

Atherosclerosis still is the first cause of mortality in the western world [1] Percutaneous Transluminal Coronary Angioplasty has proven to be an effective technique to treat sclerotic arterial disease of both coronary and peripheral arteries. Short term successrate is $85 \%$ and higher [2]. Long term successrate however is significantly lower because of restenosis. Within six months, 25 to $40 \%$ of all patients with successful first PTCA suffer from restenosis [3,4]. Many modified procedures $[5,3]$ and other recanalization techniques $[6,4]$ have been proposed, but so far none of them seem to really decrease the restenosis rate significantly. A relation between restenosis and arterial lesions resulting from balloon inflation has been suggested by several investigators, although the nature of this relation is still unclear. [7] Experiments with sinusoidally changing pressures showed that the mechanical properties of the arterial wall can be described in terms of elasticity and viscosity [8]. We therefore expect the mechanical behaviour of the arterial wall during angioplasty to be strain rate dependent. We here describe the results of our experiments to test the influence of strain rate on the strain at the moment of dissection during angioplasty.

\section{Methods}

Four segments of human femoral arteries of 10 to $12 \mathrm{~cm}$ were obtained during autopsy after informed consent of the relatives of the deceased. Directly after removal from the body, scgments were stored in glucose-free Tyrode-like solution at $4^{\circ} \mathrm{C}$. The arterial segments were cleaned from fatty tissue outside the adventitia before the experiment.
Segments were extended to physiological length in a PMMA container filled with Tyrode-solution at $37^{\circ} \mathrm{C}$ and with $\mathrm{pH}$ kept at 7.4. A balloon catheter was inflated inside the arterial segment with a syringe connected to a spindle [Vibo rolschroef, Hanco], driven by a computer controlled DCmotor [9]. The volume differences inside the balloon were measured with a Linear Variable Differential Transducer (LVDT). The diameters of the balloon and the arterial segment were measured with 2 and 4 LVDTs respectively (Jensen LDT-5L, reproducibility of mean diameter 0.012 $\mathrm{mm})$. Physiological pressure inside the artery could be varied by changing the height of a tank filled with Tyrode. Pressure inside the balloon was obtained with a Baldwin-LimaHamilton pressure transducer connected to an HBM amplifier (Hottinger Baldwin Messtechnik): Before balloon inflation the relation between the volume and diameter of the balloon was obtained. This volume diameter characterization and the minimal lumen diameter, as obtained with ultrasound, were used to apply a constant strain rate to the arterial wall. Strain was defined as the relative increase of the lumen diameter.

Experiments were performed pairwise. The strain rate in the second experiment was 10 times lower than in the first experiment. Pairs consisted of two segments of one artery, assuming the composition and mechanical properties of the two segments were alike. If three (or four) segments were available from one autopsy, strain-rate in the third (fourth) segment was equal to that in the first (or second). In this way the influence of the strain rate on the strain at the moment of dissection in almost equal segments could be measured. Inflation was stopped when one of two stopping conditions was met:

- observation of a sudden change (detected by visual inspection) in the rate of development of the balloon pressure

- a balloon pressure of 9 bar.

We previously showed that a sudden change in the development of the balloon pressure is associated with dissection of the arterial wall [10]. We thus stopped inflation at the moment of dissection of the arterial wall. 


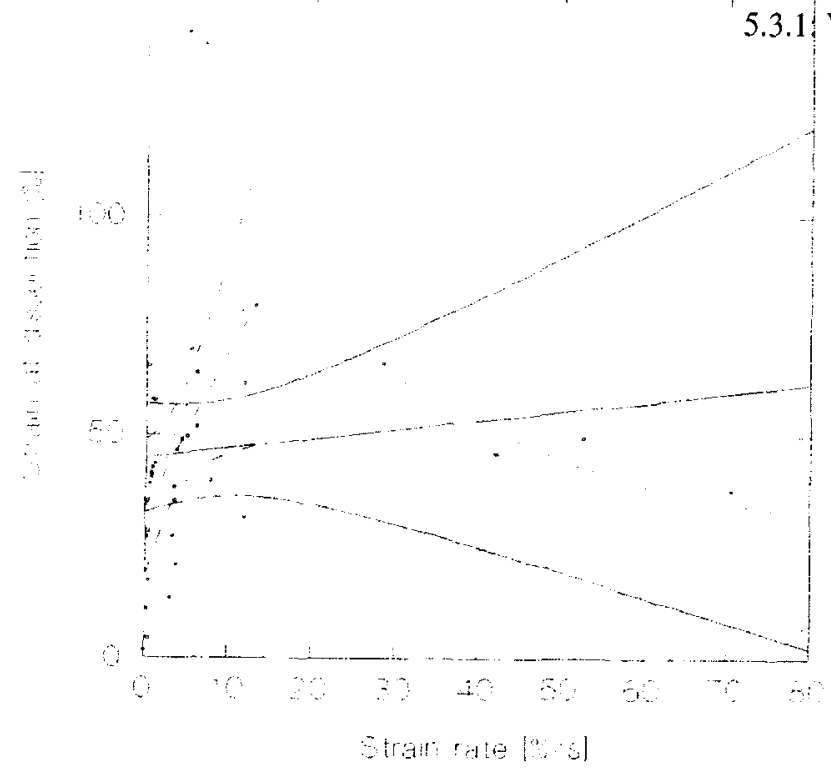

Figure 1: Applied strain rates and resulting strains at dissection during 44 angioplasty experiments. Solid line shows linear regression with 95\% confidence intervals for all experiments (strain $=43+0.042 *$ strain rate), broken line only for experiments with strain rate below $15 \% / s$ (strain $=34+$ $3.5 *$ strainrate). Curve shows $y=29+7.7 x \exp (-0.064 x)$.

\section{Results}

We performed 54 experiments with human atherosclerotic femoral arteries. For this evaluation we only used the results of the 44 experiments in which the inflation was stopped because of rupture of the arterial wall. Measured strain rates varied between 0.02 and $75 \% / \mathrm{s}$, strains at moment of arterial nupture varied between 1.8 and $141 \%$. Figure 1 shows the applied strain rates and the resulting rupture strains. These overall results show that increasing the arterial wall strain rate results in greater strain at dissection (solid line). This is clearer when only strain rates below $15 \% / \mathrm{s}$ are considered. (broken line). However, at higher strain rates the strain at dissection decreases. This suggest there is an optimal strain rate at 10 to $20 \% / \mathrm{s}$ (dotted line). The effect of strain rate on rupture strain in the various groups of segments obtained at one autopsy is shown in figure 2. It shows the applied strain rates and resulting strain at dissection for 9 groups of experiments. Most groups show a positive influence of increasing strain rate. One group had too small differences in strain rate to draw conclusions and only one group showed a negative influence of increasing strain rate. This group confirms the idea that too large strain rates diminish dissection strain. Although the slope of the correlation is not the same in all cases, the influence of strain rate is distinct. The differences in the slope could not be correlated with age or sex of the deceased, mean arterial diameter of the segments or mean arterial wall thickness.

\section{Discussion}

Our results show a distinct influence of strain rate during angioplasty on the resulting strain at dissection. They suggest there is an optimal strain rate for balloon inflation. Below this strain rate the arterial wall will be stressed too long. Like

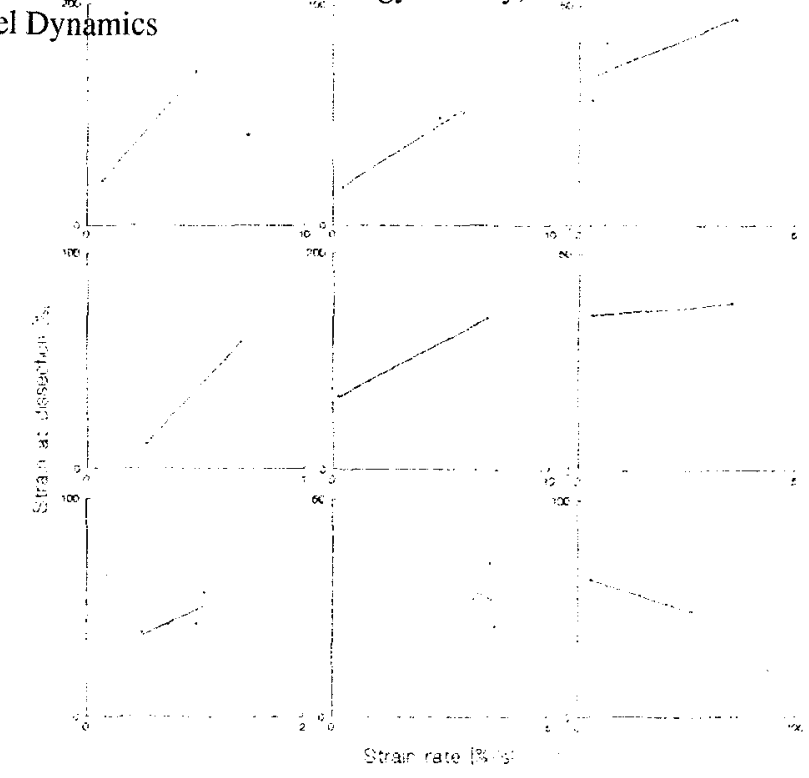

Figure 2: Applied strain rates and resulting strains at dissection during 9 groups of angioplasty expertments. Segments in one group came from one autopsy. Lines show linear regression

an elastic it will rupture even at a lower strain than during a short extension. At higher strain rates, the viscous components of the arterial wall will induce rupture. Many parameters, like age, sex, atherosclerotic severity and stenosis rate will influence arterial wall elasticity and viscosity. We found no correlation between these parameters and the slope of the relation between strainrate and strain at dissection. These parameters however will probably influence the specific value of the optimal strain rate per segment.

\section{Literature}

1 Topol EJ, Ellis SG, Cosgrove DM, Bates ER, Muller DWM. Schork NJ Schork MA, Loop FD, "Analysis of coronary angioplasty practice in the United States with an insurance-claims data base" Circulation 1993; 87; 489-497

2 Leaf A. Jorgensen MB. Jacobs AK. Cote G. Schönfeld DA. Schecr J, Weiner BH, Slack JD, Kellett MA, Raizner AE: "Do fish oils prevent restenosis after coronary angioplasty?" Circulation 1994; 90: 2248-57

3 Mattson E, "On vessel wall response to balloon dilatation; experimental studies in rabbits". Thesis University of Lund, 1992

4 Appelman YEA, Piek JJ, Strikwerda S, Tijssen JGP, de Feyter PJ, David GK, Sernuys PW, Margolis JR, Koelemay MJ, Montauban van Swijndregt EWJ, Koolen, JJ: "Randomised trial of excimer laser angioplasty versus balloon angioplasty for treatment of obstructive coronary artery disease." Lancet 1996; 347: 79-84.

5 Zocholl G, Jungbluth, Düx, Schild H, Thelen, M, "Does velocity of dilatation influence the result of dilatation." Radiology 1988: 23: 905-909.

6 Verdaasdonk RM: "Laser angioplasty with modified fiber tips." Thesis University of Utrecht 1990.

7 Roeren T, LeVeen RF, Villaneuva T, Reisman J, "Restenosis and successful angioplasty: histologic-radiologic correlation", Radiology, 1989, pp 971-977. 8 Steenhuijsen JLG, Vaartjes SR, Poortermans, CJ, Boom HBK. "In-vitro investigation on the influence of angioplasty on the mechanical properties of atherosclerotic arteries" Proc. 17th Ann. Int. Conf EMBSS, Montreal, 1995 9 Vaartjes SR, Poortermans JC, Botman MJ: In-vitro study of the biomechanics of atherosclerotic human arteries during angioplasty. Proceedings of the Technology and health care Congres; pp 127-128, Stuttgart 1993.

10 Steenhuijsen JLG, Vaartjes SR, Poortermans, CJ, Havenith MG, Boom HBK, "A method to detect rupture of the arterial wall during balloon angiopiasty" Proc. 16th Ann. Int. Conf EMBS, pp860-861, Baltimore Ma 1994 